\title{
Liquid Phase Pentanol Guerbet-Markovnikov Condensation Over VIII Group Metals
}

\author{
Irina L. Simakova*a,b, \\ Yuliya S. Demidovaa,b, Sergey A. Prikhod'ko ${ }^{a, b}$, \\ Mikhail N. Simonova,b and Anton Yu. Shabalin ${ }^{a, b}$ \\ ${ }^{a}$ Boreskov Institute of Catalysis, \\ 5, pr. Ak. Lavrentieva, Novosibirsk, 630090, Russia \\ ${ }^{b}$ Novosibirsk State University \\ 2 Pirogova, Novosibirsk, 630090, Russia
}

Received 22.03.2016, received in revised form 10.05.2016, accepted 04.06.2016

Liquid phase pentanol condensation in solutions of nonpolar hydrocarbons as well as in solventfree conditions was studied in the presence of platinum group metals (platinum, palladium, iridium, ruthenium, and rhodium) supported on mesoporous carbon support Sibunit as well as on metal oxidesalumina, zirconia and ceria. This reaction was carried out in a batch mode in the temperature range $140-200{ }^{\circ} \mathrm{C}$, under nitrogen pressure $1-10$ bar in the presence of catalysts and a base-NaOH. It was shown that pentanol condensation mainly resulted in formation of the target product 2-propylheptanol (Guerbet alcohol), whereas pentanal, 2-propyl-2-heptenal, 2-propyl-1-heptanal, 2-propyl-1-heptenol were observed in minor quantities. The effect of metals as catalysts and reaction conditions on pentanol conversion and selectivity to 2-propylheptanol was studied. The reaction temperature increase not only as expected accelerates the reaction rate but in addition improves selectivity to 2-propylheptanol. Conversion of pentanol increased in the row $\mathrm{Ir} / \mathrm{CeO}_{2}<<\mathrm{Rh} / \mathrm{Al}_{2} \mathrm{O}_{3}<\mathrm{Pd} / \mathrm{ZrO} \mathrm{O}_{2}<\mathrm{Ru} / \mathrm{C}<\mathrm{Ir} / \mathrm{C}<\mathrm{Pd} / \mathrm{C}<$ $\mathrm{Pt} / \mathrm{C}<\mathrm{Pt} / \mathrm{Al}_{2} \mathrm{O}_{3}$. Selectivity to 2-propylheptanol was elevated over metallic catalysts in the sequence $\mathrm{Ir} / \mathrm{CeO} \mathrm{O}_{2}<<\mathrm{Ir} / \mathrm{C}<\mathrm{Ru} / \mathrm{C}<\mathrm{Rh} / \mathrm{Al}_{2} \mathrm{O}_{3} \sim \mathrm{Pd} / \mathrm{C} \sim \mathrm{Pt} / \mathrm{C} \sim \mathrm{Pd} / \mathrm{ZrO}_{2} \sim \mathrm{Pt} / \mathrm{Al}_{2} \mathrm{O}_{3}$ being substantially influenced by temperature increase. The highest yield of 2-propylheptanol under comparable conditions was demonstrated for $\mathrm{Pd} / \mathrm{C}$, $\mathrm{Pt} / \mathrm{C}$ u $\mathrm{Pt}_{/} / \mathrm{Al}_{2} \mathrm{O}_{3}$ catalysts.

Keywords: pentanol, condensation, 2-propylheptanal, Guerbet alcohols, effect of metal, Ir, Rh, Pd, Pt, $R u$, mesoporous Sibunit, alumina, zirconia, ceria.

DOI: $10.17516 / 1998-2836-2016-9-2-201-211$.

(C) Siberian Federal University. All rights reserved

* Corresponding author E-mail address: simakova@catalysis.ru 


\title{
Изучение жидкофазной конденсации пентанола \\ по реакции Гербе-Марковникова \\ на металлах VIII группы
}

\author{
И.Л. Симакова ${ }^{a, \tilde{0}}$, Ю.С. Демидова ${ }^{\mathrm{a}, \tilde{\sigma}}$, \\ С.А. Приходько ${ }^{\mathrm{a}, \boldsymbol{\sigma}}$, М.Н. Симонов ${ }^{\mathrm{a}, \tilde{\sigma}}$, А.Ю. Шабалин ${ }^{\mathrm{a}, \bar{\sigma}}$ \\ ${ }^{a}$ Институт катализа им. Г.К. Борескова СО РАН \\ 5 пр. Ак. Лаврентьева, Новосибирск, 630090, Россия \\ ${ }^{\sigma}$ Новосибирский государственный университет \\ 2 ул. Пирогова, Новосибирск, 630090, Россия
}

Изучен процесс жидкофазной конденсачии н-пентанола в неполярных средах, а также в отсутствие растворителя на металлах платиновой группы (платина, палладий, иридий, рутений и родий), нанесенных на мезопористый углеродный носитель сибунит, а также оксиды металлов с различными кислотно-основными свойствами - алюминия, цииркония, церия. Реакцию проводили в автоклаве (150мл) при температуре 140-200 ${ }^{\circ}$ С, давлении азота 1-10 атм в присутствии металлов VIII группы и щелочного агента NaOH. Показано, что в ходе конденсации пентанола образуется 2-пропилгептанол (спирт Гербе), который является иелевым продуктом реакиии, а также пропаналь, 2-пропил-2-гептеналь, 2-пропил1-гептаналь, 2-пропил-1-гептенол. Исследовано влияние природы металла и условий реакиии на конверсию пентанола и селективность образования продуктов реакции. Установлено, что увеличение температуры реакиии приводит к увеличению скорости реакции и существенному росту селективности по 2-пропилгептанолу. Показано, что конверсия пентанола увеличивается в ряду катализаторов $\mathrm{Ir} / \mathrm{CeO}_{2}<<\mathrm{Rh} / \mathrm{Al}_{2} \mathrm{O}_{3}<\mathrm{Pd} / \mathrm{ZrO} \mathrm{O}_{2}<\mathrm{Ru} / \mathrm{C}<$ $\mathrm{Ir} / \mathrm{C}<\mathrm{Pd} / \mathrm{C}<\mathrm{Pt} / \mathrm{C}<\mathrm{Pt} / \mathrm{Al}_{2} \mathrm{O}_{3}$. Селективность образования 2-пропилгептанола возрастает в ряду катализаторов $\mathrm{Ir} / \mathrm{CeO}_{2}<<\mathrm{Ir} / \mathrm{C}<\mathrm{Ru} / \mathrm{C}<\mathrm{Rh} / \mathrm{Al}_{2} \mathrm{O}_{3} \sim \mathrm{Pd} / \mathrm{C} \sim \mathrm{Pt} / \mathrm{C} \sim \mathrm{Pd} / \mathrm{ZrO}_{2} \sim \mathrm{Pt} / \mathrm{Al}_{2} \mathrm{O}_{3}$ u значительно увеличивается с ростом температуры. Наибольиую эффективность в синтезе 2-пропилгептанола в сопоставимых условиях демонстрируют катализаторы $\mathrm{Pd} / \mathrm{C}, \mathrm{Pt} / \mathrm{C} u$ $\mathrm{Pt} / \mathrm{Al}_{2} \mathrm{O}_{3}$.

Ключевые слова: пентанол, конденсация, спирт Гербе, влияние металла, Ir, Rh, Pd, Pt, Ru, Сибунит, оксид алюминия, оксид ииркония, оксид иерия.

\section{Введение}

Каталитическая конденсация первичных алифатических спиртов с образованием разветвленных в $\beta$-положении спиртов протекает по так называемой реакции Гербе-Марковникова. В литературе отмечается, что данная реакция имеет большой потенциал для направленного синтеза разветвленных спиртов заданной структуры из простых моноатомных спиртов. Последовательная многократная конденсация соответствующего спирта может привести к синтезу различных моноатомных спиртов разветвленного строения, которые являются ценными интермедиатами для получения промышленных продуктов. Последующее каталитическое 
восстановление -ОН-группы спиртов позволит целенаправленно получать разветвленные углеводороды, идентичные компонентам авиационного топлива [1]. В большинстве работ, посвященных исследованию механизма реакции Гербе-Марковникова, предполагается, что реакция включает четыре разных типа последовательных превращений: дегидрирование, альдольную конденсацию, дегидратацию и гидрирование [2, 3]. В некоторых исследованиях представлен альтернативный механизм образования сложных спиртов через прямое поверхностное взаимодействие субстратов, сопровождающееся отщеплением ОН-группы от одной молекулы спирта и водорода в $\alpha$-положении от второй [3]. Однако независимо от типа механизма, согласно проведенным исследованиям, было показано, что скорость превращений, протекающих в рамках реакции Гербе-Марковникова, существенно зависит от кислотно-основных свойств каталитической системы [3]. В самых ранних работах для реакции Гербе-Марковникова в качестве катализаторов были предложены различные оксидные катализаторы, включая оксид меди, свинца, цинка, хрома, молибдена, вольфрама, магния, алюминия, а также соли никеля и свинца и их смеси [4-8]. Позднее эта реакция исследовалась в присутствии солей щелочных металлов и оксида алюминия в сочетании с металлами платиновой группы, медью или никелем [9-13]. В большинстве случаев реакцию проводили при повышенной температуре (473-853 К) и давлении азота или водорода (6-14 МПа) как в проточном, так и статическом реакторах. Однако селективность образования целевого продукта не превышала 40 \% для самого активного катализатора. Таким образом, несмотря на очевидную актуальность и перспективность селективного превращения первичных спиртов в ценные химические реагенты, данное направление еще недостаточно изучено, особенно в области целенаправленного синтеза катализаторов, селективных в отношении реакций дегидрирования/конденсации/гидрирования.

Цель настоящей работы - выяснение влияния природы металла ( $\mathrm{Ir}, \mathrm{Rh}, \mathrm{Pd}, \mathrm{Pt}$ и Ru) и носителя на селективность образования спирта Гербе в процессе жидкофазной конденсации $\mu$-пентанола по реакции Гербе-Марковникова в инертной атмосфере в присутствии катализаторов на основе металлов VIII группы.

\section{Экспериментальная часть}

\section{Реагенты}

В работе использовали $н$-пентанол (99 \% основного вещества, Acros Organics, Belgium), декан (ТУ 6-09-659-73 ХЧ), азот (СОВ не менее 99,95 \%, ГОСТ 9293-74), водород технический марки Б (СОВ не менее 99,95 \%, ГОСТ 3022-80) без дополнительной очистки. Для синтеза катализаторов брали $\mathrm{Al}_{2} \mathrm{O}_{3}\left(\mathrm{~S}_{\mathrm{yд}}=129 \mathrm{~m}^{2} / \Gamma\right)$, оксид циркония $\mathrm{ZrO}_{2}$ (Acros Organics, $\mathrm{S}_{\mathrm{yд}}=106 \mathrm{~m}^{2} / \Gamma$ ), оксид церия $\mathrm{CeO}_{2}\left(\mathrm{~S}_{\mathrm{yд}}=29 \mathrm{~m}^{2} / \Gamma\right)$, мезопористый углеродный носитель Сибунит $\left(\mathrm{S}_{\mathrm{yд}}=352 \mathrm{~m}^{2} / \Gamma\right)$. В качестве предшественников активного компонента выступали следующие реагенты: хлорид палладия $\mathrm{PdCl}_{2}$ (ТУ 6-09-2025-84 Реахим, г. Москва), платинохлористоводородная 6-водная кислота $\mathrm{H}_{2} \mathrm{PtCl}_{6}$ (ТУ 2612-034-00205067-2003 ОАО АУРАТ, г. Москва), гидрат хлорида рутения $\mathrm{RuCl}_{3}$ (ТУ 2625-066-00196533-2002 Красцветмет, г. Красноярск), 4-водный хлорид родия $\mathrm{RhCl}_{3}$ (ТУ 2625-047-00205067-2003 ОАО АУРАТ, г. Москва) и гидрат хлорид иридия $\mathrm{IrCl}_{3}$ (ТУ 2625-067-00196533-2002 ОАО «Красноярский завод цветных металлов имени В.Н. Гулидова», г. Красноярск). 


\section{Синтез катализаторов гидрирования}

Катализаторы 4 \% Ir/CeO $\mathrm{Ce}_{2}, 5$ \% Rh/ $/ \mathrm{Al}_{2} \mathrm{O}_{3}, 4$ \% Pd/ZrO $2,3 \% \mathrm{Pt} / \mathrm{Al}_{2} \mathrm{O}_{3}, 3$ \% Ir/C, 3 \% Ru/C, $3 \% \mathrm{Pt} / \mathrm{C}, 6 \% \mathrm{Pd} / \mathrm{C}$ получали нанесением раствора предшественника соответствующего металла на оксид металла или углеродный носитель с последующей сушкой и восстановлением. После высушивания при $110^{\circ} \mathrm{C}$ в течение 17 ч катализаторы восстанавливали молекулярным водородом, поднимая рабочую температуру до температуры не ниже определенной при исследовании соответствующих катализаторов методом ТПВ. Катализатор перед выгрузкой из реактора пассивировали газообразным азотом, содержащим $\sim 0,002$ об. \% кислорода.

\section{Физико-химические методы анализа}

Определение процентного содержания металла на углеродном носителе проводили рентгеноспектральным методом на флуоресцентном анализаторе VRA-30 с Cr-анодом рентгеновской трубки.

Спектры РФЭС были записаны на фотоэлектронном спектрометре SPECS с использованием немонохроматизированного излучения $\mathrm{AlKa}(\mathrm{hn}=1486,61$ эB, 205 Вт). Шкала энергий связи ( $\mathrm{E}_{\mathrm{cв}}$ ) была предварительно откалибрована по положению пиков основных уровней металлического золота и меди: Au4f7/2 (84,0 эB) и Cu2p3/2 (932,67 эВ). Обзорные спектры записывали при энергии пропускания анализатора 50 эВ, отдельные спектральные районы - 10 и 20 эВ.

Анализ методом ПЭМВР проводили на просвечивающем электронном микроскопе высокого разрешения «ЈЕМ-2010» (Япония) с разрешением по решетке 0,14 нм и ускоряющим напряжением 200 кВ. Средний диаметр частиц (не менее 250 частиц) рассчитывали по следующей формуле:

$$
d_{m}=\frac{\sum_{i}\left(x_{i} d_{i}\right)}{\sum_{i} x_{i}},
$$

где $x_{i}$ - число частиц с диаметром $d_{i}$.

Исследования носителя и нанесенных катализаторов методом ТГ-ДТА-МС были выполнены на приборе Netzsch STA 409 PC, сопряженном с масс-спектрометром SRS UGA 200. Измерения проводили с использованием корундовых тиглей. Прободержатель ДТА вместе с тиглями был предварительно прогрет до $1000^{\circ} \mathrm{C}$ в потоке воздуха. Кривые коррекции были записаны в соответствии с требованиями эксперимента от 50 до $600^{\circ} \mathrm{C}$ со скоростью $10 \%$ мин в токе аргона, затем в смеси аргона и водорода. Навеска образца составляла 50-52 мг. После загрузки образца и установки тигля на держатель температуру поднимали до $50{ }^{\circ} \mathrm{C}$ и выдерживали 1 ч для установления теплового равновесия. Термические кривые образцов были записаны в диапазоне от 50 до $600{ }^{\circ} \mathrm{C}$ со скоростью нагрева $10 \%$ мин в атмосфере аргона с использованием 15\%-ной смеси водорода в аргоне (20 мл/мин), дополнительно разбавленной аргоном, подаваемым на весы прибора (20 мл/мин). Полученные данные были обработаны с помощью программы Netzsch Proteus Analysis и затем совмещены с данными массспектрометра в программе OriginPro 7,5G. 


\section{Методика проведения реакиии конденсачии н-пентанола}

Эксперименты по жидкофазной конденсации пентанола в неполярном растворителе (декане) и в отсутствие растворителя проводили в автоклаве (150 мл) из нержавеющей стали с перемешиванием при постоянном давлении азота 1-25 атм при $140-200{ }^{\circ} \mathrm{C}$. Загрузка пентанола -3 мл, декан (октан) - 12 мл, в отсутствие растворителя загрузка пентанола - 15 мл.

Идентификацию конденсированных продуктов проводили методом хроматомассспектроскопии на приборах VG-7070 GC/MS (колонка 30 м х 0,25 мм х 0,25 мкм ZB-Wax) и Agilent 5973N EI/PCI (колонка 30 х 0,25 мм VF-5ms). Количественный анализ состава продуктов реакции определяли методом ГЖХ на хроматографе «Хромос ГХ-1000» с пламенноионизационным детектором и кварцевой капиллярной колонкой ВР20 60 м/0,25 мм/0,25 мкм при температуре 323-473 К со скоростью нагрева 10 К/мин для анализа жидкой фазы и при температуре 373-413 К для анализа газовой фазы, температура детектора и испарителя состав-

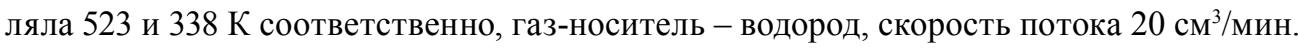

\section{Результаты и обсуждение}

Реакции жидкофазной конденсации $\mu$-пентанола изучали в присутствии катализаторов после их предварительного восстановления, аналогично гидрированию карбоксильной группы молочной [14-16] и валериановой кислот [17]. В соответствии с полученными данными ТПВ были определены оптимальные условия высокотемпературной восстановительной обработки для полученных катализаторов. Восстановление нанесенных катализаторов проводили, поднимая температуру до $360{ }^{\circ} \mathrm{C}$, что обеспечивало полное восстановление прекурсоров до металлического состояния в соответствии с данными ТПВ, представленными для $\mathrm{Pt} / \mathrm{C}$ (рис. 1) и $\mathrm{Ru} / \mathrm{C}$ (рис. 2).

Методом РФЭС было установлено, что активные компоненты катализаторов $\mathrm{Ir} / \mathrm{CeO}_{2}$, $\mathrm{Rh} / \mathrm{Al}_{2} \mathrm{O}_{3}, \mathrm{Ir} / \mathrm{C}, \mathrm{Ru} / \mathrm{C}, \mathrm{Pt} / \mathrm{C}, \mathrm{Pd} / \mathrm{ZrO}_{2}, \mathrm{Pd} / \mathrm{C}, \mathrm{Pt} / \mathrm{Al}_{2} \mathrm{O}_{3}$ представляют металлические частицы с незначительной долей окисленного металла, за исключением $\mathrm{Ir} / \mathrm{CeO}_{2}$, в котором содержание окисленного состояния иридия немного выше, что обусловлено, по-видимому, влиянием носителя, содержащего подвижный кислород. Можно предположить, что в условиях реакции, в

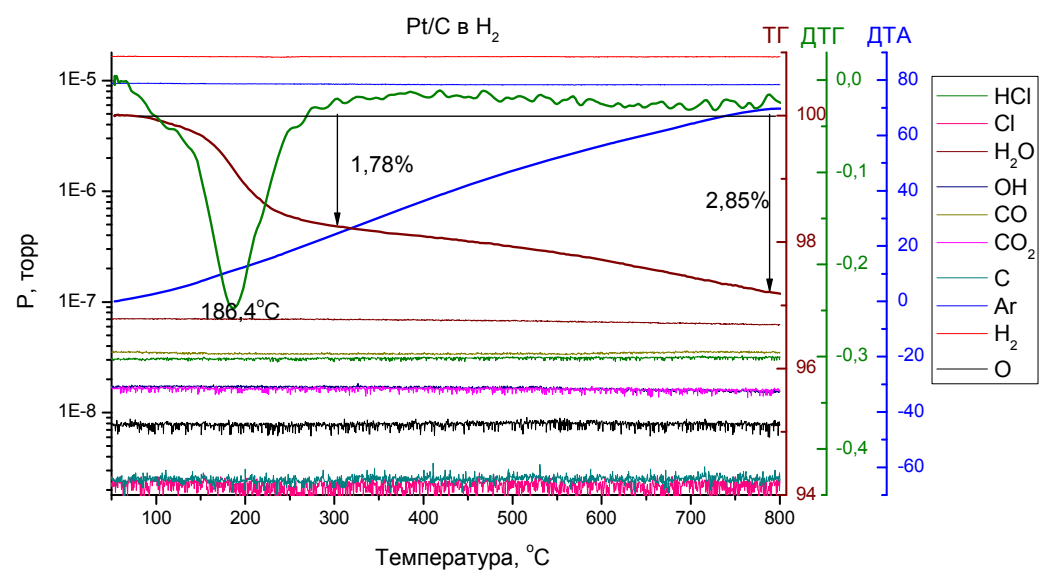

Рис. 1. Данные метода ТГ-ДТА-МС для $\mathrm{H}_{2} \mathrm{PtCl}_{6} / \mathrm{C}$

$$
-205-
$$


ходе которой за счет дегидрирования $н$-пентанола (2 молекул) с образованием пентаналя (2 молекул) генерируется in-situ 2-й молекулы $\mathrm{H}_{2}$, окисленная фаза активного компонента претерпевает обратные восстановительные изменения, при этом генерируемый молекулярный водород расходуется преимущественно на гидрирование $\mathrm{C}=\mathrm{C}$ - и $\mathrm{C}=\mathrm{O}$-связей интермедиатов («еналя», «енола» и «аналя») с образованием разветвленного в $\beta$-положении спирта Гербе.

Согласно данным просвечивающей электронной микроскопии высокого разрешения, катализаторы $\mathrm{Ir} / \mathrm{CeO}_{2}, \mathrm{Pd} / \mathrm{ZrO}_{2}, \mathrm{Rh} / \mathrm{Al}_{2} \mathrm{O}_{3}, \mathrm{Pt} / \mathrm{Al}_{2} \mathrm{O}_{3}, \mathrm{Ir} / \mathrm{C}, \mathrm{Ru} / \mathrm{C}$ (рис. 3), $\mathrm{Pt} / \mathrm{C}$ (рис. $4 a$ ), $\mathrm{Pd} / \mathrm{C}$ представляют собой нанодисперсные частицы активного металла сферической формы, равномерно распределенные по поверхности носителя. Средний размер частиц активного компонента варьируется от 1.0 до 1.5 нм. Исключением является катализатор $\mathrm{Pd} / \mathrm{C}$ с содержанием активного компонента 6 вес. \%, для которого средний размер частиц Рd находится в интервале 2.3-2.9 нм.

Учитывая примерно одинаковое атомное содержание металла в катализаторах, что было подтверждено результатами рентгенофлуоресцентного метода анализа, можно считать, что

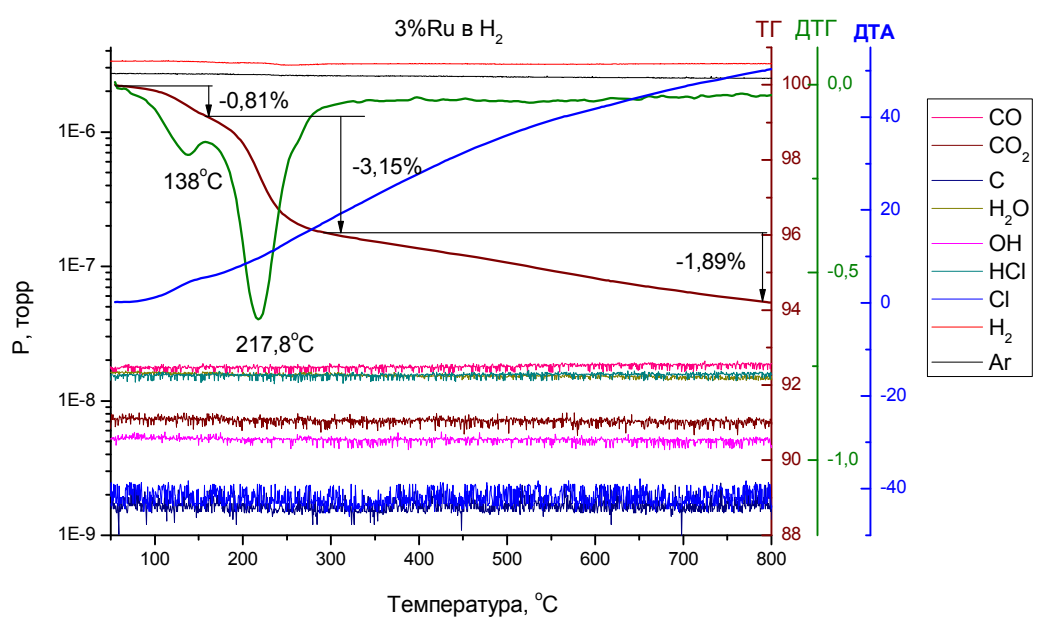

Рис. 2. Данные метода ТГ-ДТА-МС для $\mathrm{RuCl}_{3} / \mathrm{C}$
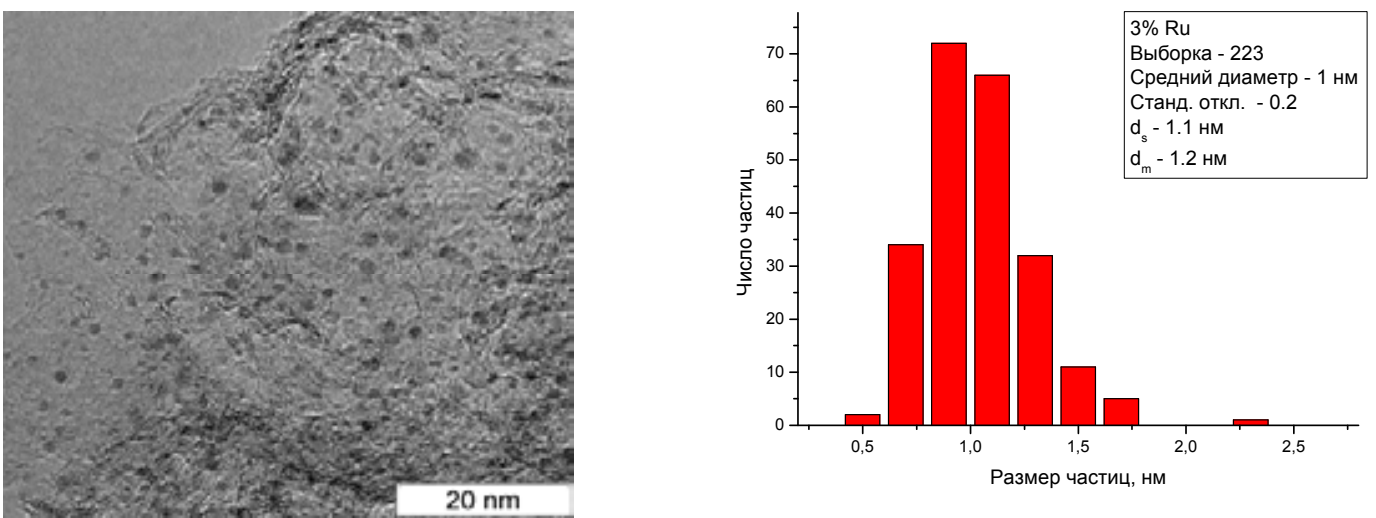

Рис. 3. Микрофотографии ПЭМ и гистограммы распределения частиц по размерам для катализатора 3 \% $\mathrm{Ru} / \mathrm{C}$ до реакции конденсации $\boldsymbol{H}$-пентанола 
удельные поверхности активного компонента в навесках катализаторов одинаковой массы имеют сопоставимые значения.

Согласно данным ГЖХ-анализа, основными продуктами реакции конденсации $\boldsymbol{t}$-пентанола являются 2-пропилгептанол (спирт Гербе), целевой продукт реакции, а также промежуточные - пентаналь, 2-пропил-2-гептеналь, 2-пропил-1-гептаналь, 2-пропил-1-гептенол (рис. 5).
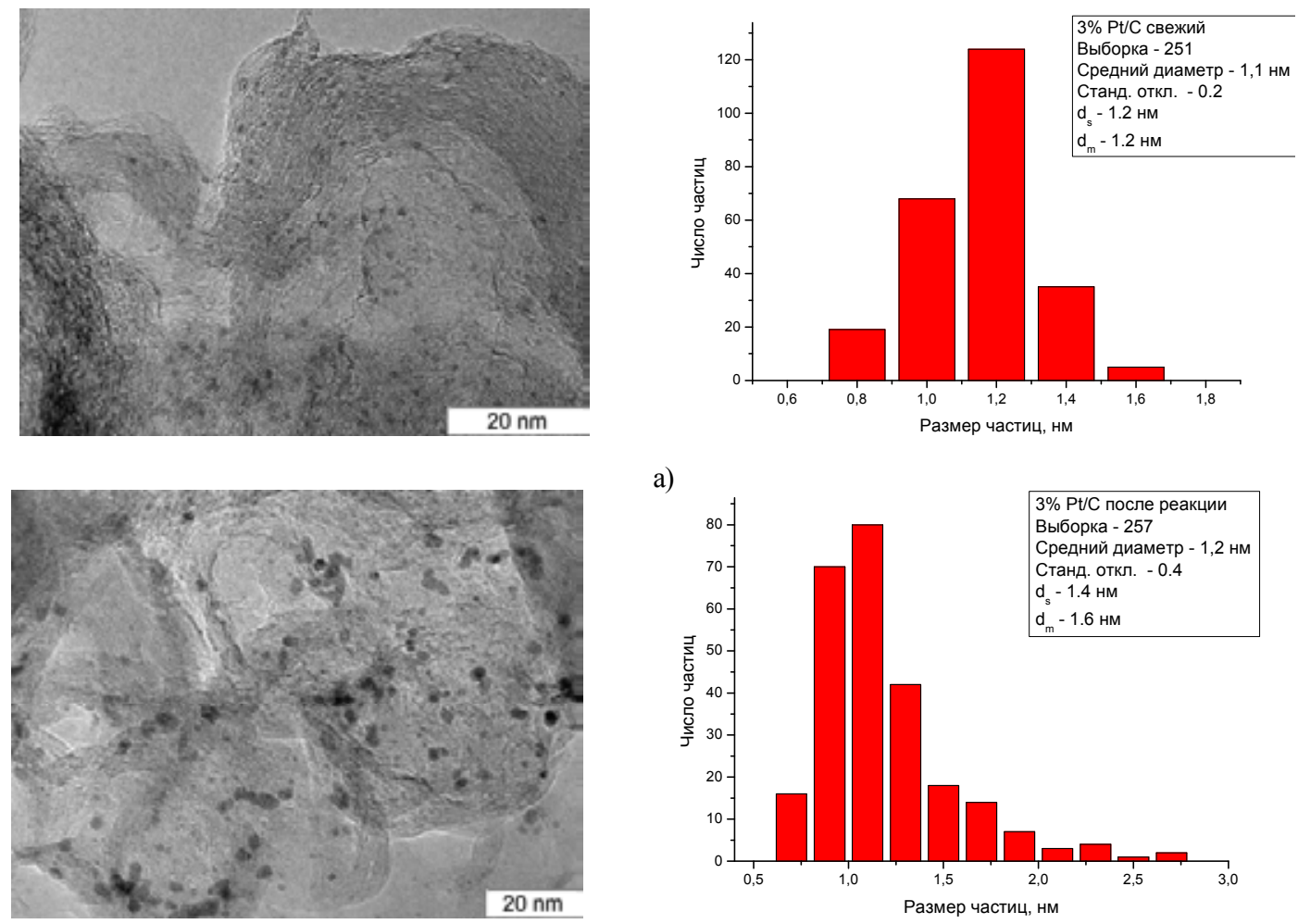

a)

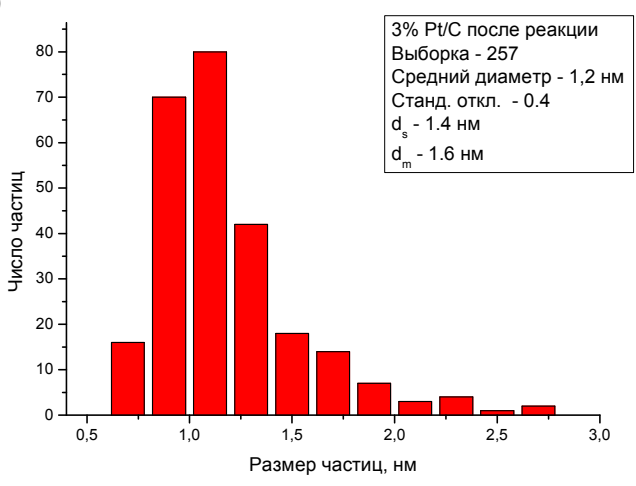

б)

Рис. 4. Микрофотографии ПЭМ и гистограммы распределения частиц по размерам для катализатора 3 \% $\mathrm{Pt} / \mathrm{C}$ до реакции (а) и после реакции (б) конденсации $\boldsymbol{H}$-пентанола. Условия реакции: температура $160{ }^{\circ} \mathrm{C}$, давление $\mathrm{N}_{2} 10$ атм, $\boldsymbol{H}$-пентанол 15 мл, катализатор 3 \% Pt/C 0.1 г, $\mathrm{NaOH} 0.1$ г

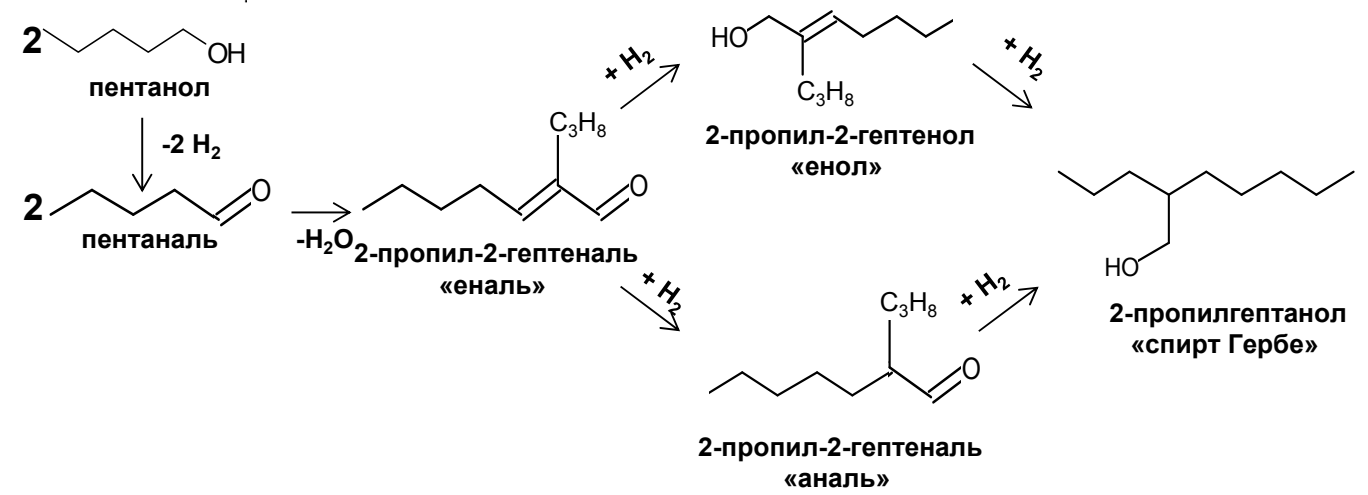

Рис. 5. Общая схема реакции конденсации $\mu$-пентанола 
При высоких значениях конверсии $\mu$-пентанола наблюдается появление тяжелых продуктов, по-видимому, за счет последующей межмолекулярной конденсации целевого продукта 2-пропилгептанола и его кросс-конденсации с исходным $t$-пентанолом, а также за счет возможных побочных реакций гидрогенолиза, деоксигенирования и гидрирования кислородсодержащих функционалов групп (рис. 5). Изучение реакции конденсации проводили при конверсиях н-пентанола, не превышающих 13 \%. Предварительные эксперименты показали, что разбавление $t$-пентанола растворителем (деканом) приводит к снижению конверсии пентанола с 11.9 до 5.7 \% при одновременном снижении содержания целевого продукта (2-пропилгептанола) в реакционной смеси с 10.7 до $1.8 \%$ за 3.5 ч реакции в присутствии $\mathrm{Pt} / \mathrm{C}$. В табл. 1 представлены результаты каталитической конденсации пентанола на металлах VIII группы $\mathrm{Ir} / \mathrm{CeO}_{2}$, $\mathrm{Rh} / \mathrm{Al}_{2} \mathrm{O}_{3}, \mathrm{Pd} / \mathrm{ZrO}_{2}, \mathrm{Pt} / \mathrm{Al}_{2} \mathrm{O}_{3}, \mathrm{Ir} / \mathrm{C}, \mathrm{Ru} / \mathrm{C}, \mathrm{Pt} / \mathrm{C}$ и $\mathrm{Pd} / \mathrm{C}$ в отсутствие растворителя, рассчитанные по данным ГЖХ-анализа.

Конверсия пентанола увеличивается в ряду катализаторов: $\mathrm{Ir} / \mathrm{CeO}_{2}<<\mathrm{Rh} / \mathrm{Al}_{2} \mathrm{O}_{3}<\mathrm{Pd} / \mathrm{ZrO}_{2}$ $<\mathrm{Ru} / \mathrm{C}<\mathrm{Ir} / \mathrm{C}<\mathrm{Pd} / \mathrm{C}<\mathrm{Pt} / \mathrm{C}<\mathrm{Pt} / \mathrm{Al}_{2} \mathrm{O}_{3}$. Селективность образования 2-пропилгептанола возрастает в ряду катализаторов: $\mathrm{Ir} / \mathrm{CeO}_{2}<<\mathrm{Ir} / \mathrm{C}<\mathrm{Ru} / \mathrm{C}<\mathrm{Rh} / \mathrm{Al}_{2} \mathrm{O}_{3} \sim \mathrm{Pd} / \mathrm{C} \sim \mathrm{Pt} / \mathrm{C} \sim \mathrm{Pd} / \mathrm{ZrO}{ }_{2} \sim \mathrm{Pt} / \mathrm{Al}_{2} \mathrm{O}_{3}$. Наибольшую эффективность в синтезе 2-пропилгептанола демонстрируют катализаторы $\mathrm{Pd} / \mathrm{C}$, $\mathrm{Pt} / \mathrm{C}$ и $\mathrm{Pt} / \mathrm{Al}_{2} \mathrm{O}_{3}$.

Исследование влияния температуры реакции на конверсию и селективность образования целевого продукта, 5-нонанола, было проведено в присутствии Pt катализаторов, нанесенных на углеродный носитель. Результаты экспериментов, рассчитанные по данным ГХМС анализа, показали, что с повышением температуры реакции от 140 (рис. 6) до $180{ }^{\circ} \mathrm{C}$ (рис. 7) увеличивается как скорость превращения пентанола, так и селективность образования 2-пропилгептанола, причем при $180{ }^{\circ} \mathrm{C}$ побочный продукт 2-пропил-2-гептенол не был обнаружен ни в ходе реакции, ни в конечной реакционной смеси (рис. 7). Наблюдаемые различия в селективности образования 2-пропилгептанола могут быть связаны с более эффективным переносом водорода при более высокой температуре для гидрирования ненасыщенных свя-

Таблица 1. Влияние условий реакции на выход продуктов конденсации пентанола (по данным ГЖХанализа). Условия реакции: н-пентанол - 15 мл, катализатор 3 \% Pt/C -0.1 г, $\mathrm{NaOH}-0.1$ г, температура $180^{\circ} \mathrm{C}$, давление азота 10 атм (постоянное)

\begin{tabular}{|c|c|c|c|c|c|}
\hline Номер & Катализатор & $\begin{array}{c}\text { Время } \\
\text { реакции, ч }\end{array}$ & $\begin{array}{c}\text { Конверсия } \\
\text { пентанола, \% }\end{array}$ & $\begin{array}{c}\text { Селективность } \\
\text { образования } \\
\text { 2-пропилгептанола, \% }\end{array}$ & $\begin{array}{c}\text { Выход } \\
\text { 2-пропилгептанола, \% }\end{array}$ \\
\hline 1 & $\mathrm{Ir} / \mathrm{CeO}_{2}$ & 4 & 2.4 & 0 & 0 \\
\hline 2 & $\mathrm{Rh} / \mathrm{Al}_{2} \mathrm{O}_{3}$ & 4 & 2.5 & 76.0 & 1.9 \\
\hline 3 & $\mathrm{Pt} / \mathrm{Al}_{2} \mathrm{O}_{3}$ & 3.6 & 11.9 & 89.9 & 10.7 \\
\hline 4 & $\mathrm{Pd} / \mathrm{ZrO}_{2}$ & 3.5 & 4.7 & 89.4 & 4.2 \\
\hline 5 & $\mathrm{Ir} / \mathrm{C}$ & 4.0 & 8.4 & 23.8 & 2.0 \\
\hline 6 & $\mathrm{Ru} / \mathrm{C}$ & 4.0 & 5.5 & 30.9 & 1.7 \\
\hline 8 & $\mathrm{Pd} / \mathrm{C}$ & 1.0 & 6.6 & 77.3 & 5.1 \\
\hline 7 & $\mathrm{Pt} / \mathrm{C}$ & 0.5 & 4.1 & 75.6 & 3.1 \\
\hline
\end{tabular}




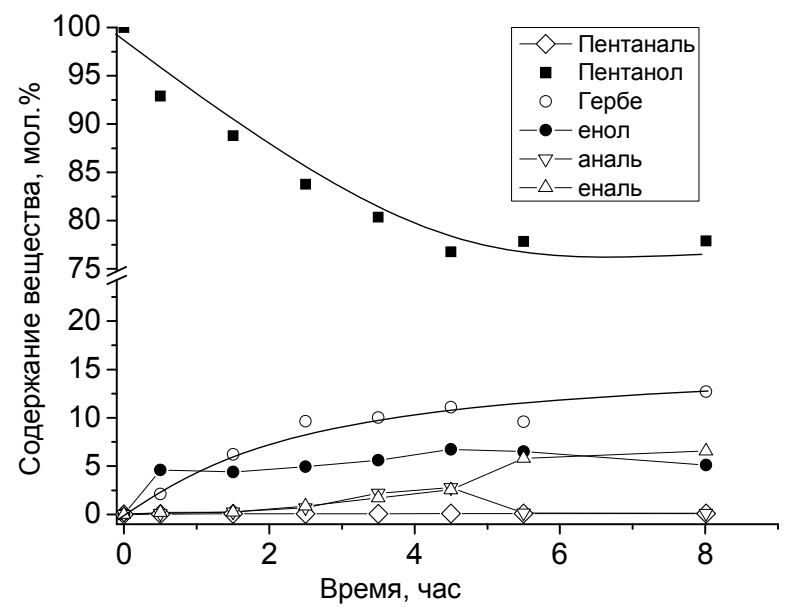

Рис. 6. Зависимость содержания продуктов конденсации пентанола от времени. Условия реакции: температура $140{ }^{\circ} \mathrm{C}$, давление $\mathrm{N}_{2} 10$ атм, $H$-пентанол 15 мл, 3 \% Pt/C 0.1 г, NaOH 0.1 г

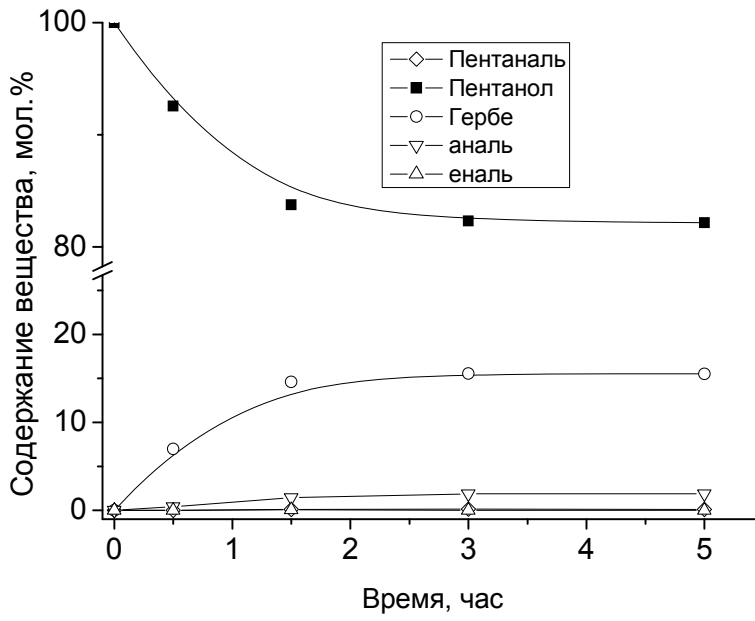

Рис. 7. Зависимость содержания продуктов конденсации пентанола от времени. Условия реакции: температура $180{ }^{\circ} \mathrm{C}$, давление $\mathrm{N}_{2} 10$ атм, $\mu$-пентанол 15 мл, катализатор 3 \% Pt/C 0.1 г, $\mathrm{NaOH} 0.1$ г

зей, о чем свидетельствует отсутствие в реакционной смеси спирта Гербе с ненасыщенной $\mathrm{C}=\mathrm{C}$-связью («енол»).

Кинетический профиль кривых распределения продуктов от времени реакции (рис. 6, 7) свидетельствует об уменьшении скорости превращения пентанола и остановке реакции независимо от температуры её проведения. Это может указывать на дезактивацию катализатора, так как реакция не запрещена термодинамикой [2]. Возможными причинами снижения активности могут быть агломерация активного компонента в ходе реакции, его окисление или блокирование активных центров побочными продуктами реакции. Для выяснения причин дезактивации образцы $\mathrm{Pt} / \mathrm{C}$ катализатора были изучены методом ПЭМ до и после реакции (рис. $4 a$ и б). На гистограммах распределения частиц по размерам для отработанного катализатора

$$
-209-
$$


наблюдается небольшое увеличение доли крупных частиц Pt по сравнению с исходным образцом. Такое незначительное увеличение среднего размера частиц Pt (c 1.1 до 1.2 нм) едва ли могло стать причиной значительного снижения каталитической активности. Наиболее вероятной причиной дезактивации может быть окисление активного компонента, приводящее к снижению скорости образования пентаналя и молекулярного водорода. В свою очередь, низкое содержание пентаналя, необходимого для протекания последующей альдольной конденсации, а также недостаток молекулярного водорода, необходимого для последующего гидрирования ненасыщенных интермедиатов альдольной конденсации и регенерации металлического состояния активного компонента, приводят к остановке реакции. Низкое содержание пентаналя может быть обусловлено также его быстрой последующей конденсацией. Однако содержание продуктов конденсации 2-пропил-1-гептеналя в реакционной смеси также мало (рис. 6, 7). Отдельные эксперименты с пентаналем показали, что его конденсация происходит в присутствии щелочи без катализатора, следовательно, низкое содержание пентаналя связано не с его быстрым превращением в 2-пропил-2-гептеналь, а с низкой скоростью его образования на стадии дегидрирования пентанола. Определение оптимального соотношения между $\mathrm{Pt}^{\circ}$ и $\mathrm{Pt}^{\delta+}$, необходимого для поддержания катализатора в активном состоянии на стадии дегидрирования, не входит в задачу данной работы и требует отдельного детального исследования, связанного с изучения динамики работающего катализатора. Следует отметить, что блокировка активных центров Pt высокомолекулярными продуктами побочных реакций также может быть одной из причин снижения активности катализатора.

Полученные результаты указывают на то, что среди металлов VIII группы Ir проявляет наименьшую активность в превращении пентанола в спирт Гербе, в то время как каталитические системы на основе $\mathrm{Pd}$ и $\mathrm{Pt}$ достаточно эффективны для осуществления одностадийной конденсации спиртов в мягких условиях, обеспечивая селективность по 2-пропилгептанолу $\sim 80 \%$. При этом проведение реакции при более высоких температурах и давлениях благоприятствует повышению скорости реакции и селективности по целевому продукту. Среди исследованных неорганических носителей щелочной оксид церия и амфотерный оксид циркония являются наименее эффективными. Наиболее высокий выход целевого спирта 2-пропилгептанола был получен на металлах, нанесенных на углеродный носитель и оксид алюминия. Роль носителя и его микротекстурных свойств необходимо в дальнейшем детально исследовать для определения оптимальных параметров носителя. Кроме того, для определения оптимального размера активного компонента в составе наиболее эффективных Pd- и Рt-катализаторов необходимо изучить влияние размера частиц на скорость и селективность реакции.

Авторы благодарны сотрудникам ИК СО РАН к.Х.н. Н.В. Штерцер за исследование образцов методом ТПВ, к.ф.-м.н. Е.Ю. Герасимову за исследование образцов методом ПЭМ, К.Х.н. И.П. Просвирину за исследование образцов методом РФЭС и И.Л. Краевской за исследование образцов рентгенофлюоресцентным методом анализа, а также проф. Д.Ю. Мурзину (Университет Або Академии, Финлянди, г. Турку) за обсуждение полученных результатов.

Авторы признательны Российскому фонду фундаментальных исследований (грант № 15-03-09329) за финансовую поддержжку работы. 


\section{Список литературы}

1. Alonso D.M., Bond J.Q., Serrano-Ruiz J.C., Dumesic J.A. Production of liquid hydrocarbon transportation fuels by oligomerization of biomass-derived C9 alkenes. Green Chem. 2010. Vol. 12, P. 992-999.

2. Gabriels D., Hernandez W.Y., Sels B., Van der Voort P., Verberckmoes A. Review of catalytic systems and thermodynamics fort he Guerbet condensation reaction and challenges for biomass valorization. Catal. Sci. Technol. 2015. Vol. 5, P. 3876-3902.

3. Kozlowski J.T., Davis R.J. Heterogeneous catalysts for the Guerbet coupling of alcohols. ACS Catal. 2013. Vol. 3 (7), P. 1588-1600.

4. Fuchs O., U.S. Patent 1,992,480 1931.

5. Wibaut J.P., U.S. Patent 1,910,582 1933.

6. Fuchs O., U.S. Patent 2,092,450 1937.

7. Burgoyne E.E., U.S. Patent 2,645,667 1951.

8. O’Lenick A.J., J. Surfactants Deterg., 4 (2001) 311- 315.

9. Miller R.E., Bennett G.E., U.S. Patent 2,762,847 1956.

10. Miller R.E., U.S. Patent 2,836,628 1958.

11. Farrar M.W., Groves W., U.S. Patent 2,971,033 1961.

12. Pregaglia G., Gregorio G., U.S. Patent 3,514,493 1970.

13. Clark R., U.S. Patent 3,972,952 1976.

14. Simonov M.N., Simakova I.L., Parmon V.N. Hydrogenation of lactic acid to propylene glycol over copper-containing catalysts. React. Kin. Cat. Lett. 2009. Vol. 97 (1), P. 157-162.

15. Simonov M.N., Simakova I.L., Minyukova T.P., Khassin A.A. Hydrogenation of lactic acid to propylene glycol over reduced copper-containing catalysts. Russ. Chem. Bull. 2009. Vol. 6, P. 10861090.

16. Simonov M., Zaikin P., Simakova I. Highly selective catalytic propylene glycol synthesis from alkyl lactate over copper on silica: performance and mechanism. Applied Catalysis B: Environmental 2012. Vol. 119- 120, P. 340- 347.

17. Симакова И.Л., Демидова Ю.С., Приходько С.А., Симонов М.Н., Шабалин А.Ю. Каталитическое гидрирование пентановой кислоты на металлах VIII группы. Журнал Сибирского федерального университета. Химия. 2015. Т. 3, С. 439-449. 